\title{
Optical, Structural and Morphological Properties of Photocatalytic ZnO Thin Films Deposited by Pray Pyrolysis Technique
}

\author{
Durgam Komaraiah, Eppa Radha, Y. Vijayakumar, J. Sivakumar, M. V. Ramana Reddy, R. Sayanna \\ Department of Physics, University College of Science, Osmania University, Hyderabad, India \\ Email: dkumarou@gmail.com
}

How to cite this paper: Komaraiah, D., Radha, E., Vijayakumar, Y., Sivakumar, J., Reddy, M.V.R. and Sayanna, R. (2016) Optical, Structural and Morphological Properties of Photocatalytic ZnO Thin Films Deposited by Pray Pyrolysis Technique. Modern Research in Catalysis, 5, 130-146. http://dx.doi.org/10.4236/mrc.2016.54011

Received: September 10, 2016

Accepted: October 18, 2016

Published: October 21, 2016

Copyright $\odot 2016$ by authors and Scientific Research Publishing Inc. This work is licensed under the Creative Commons Attribution International License (CC BY 4.0).

http://creativecommons.org/licenses/by/4.0/

\begin{abstract}
Photocatalytic $\mathrm{ZnO}$ thin films have been deposited onto glass substrate by spray pyrolysis technique. The sprayed solution consists of $0.1 \mathrm{M}$ of zinc acetate dihydrate dissolved in double distilled water and sprays onto ultrasonically cleaned glass substrates maintained at $350^{\circ} \mathrm{C}$, through an air-atomizing nozzle. The X-ray diffraction (XRD), scanning electron microscopy (SEM), EDX and UV-VIS spectrophotometer were applied to describe the structural, morphological, compositional and optical properties of $\mathrm{ZnO}$ catalyst. XRD analysis confirms that the films were found to be single phase hexagonal wurtzite structure. The SEM micrograph of the films is shown highly uniform, crack free and found to be fiber like structures. The optical transmittance spectra of the $\mathrm{ZnO}$ thin films were found to be transparent to visible light and the average optical transmittance was greater than $85 \%$. The direct optical band gap energy values of the films shift towards the lower energy as a consequence of the thermal annealing. The Urbach energy of the films was found to increase with annealing temperature. The refractive index of the films was calculated and the refractive index dispersion curve of the films obeys the single oscillator model. The values of oscillatory energy $E_{\mathrm{o}}$, dispersion energy $\mathrm{E}_{\mathrm{d}}$, and static dielectric constant $\varepsilon_{\mathrm{s}}$ for the $\mathrm{ZnO}$ thin films were determined. The films were evaluated for their ability to degrade methylene blue. The Langmuir-Hinshelwood kinetic model was used to interpret quantitatively the observed kinetic experimental result. The photocatalytic activity of $\mathrm{ZnO}$ thin films was enhanced by annealing temperature.
\end{abstract}

\section{Keywords}

ZnO Thin Film, Spray Pyrolysis, Optical Band Gap, Refractive Index, Photo Catalysis

\section{Introduction}

Zinc oxide $(\mathrm{ZnO})$ is an n-type semiconductor, has a hexagonal wurtzite structure, and 
has been extensively studied in recent years owing to its technical importance. $\mathrm{ZnO}$ is widely used as a functional material because it has a direct band gap of $3.37 \mathrm{eV}$, high electron mobility, and large exciton binding energy $(\sim 60 \mathrm{meV})$ at room temperature [1]. It has excellent chemical and thermal stability, low cost, richly abundant, environment-friendly, non-toxic nature, strong oxidizing power, high photosensitivity, and high resistance to radiation damage. $\mathrm{ZnO}$ has now received increasing attention and recognized as a promising material because of its vast potential in many scientific and industrial areas as a micro-electronic and opto-electronic devices such as light emitting diodes [2], thin film transistors [3] [4], Varistors [5], solar cells [6] [7] [8], gas sensors [9] [10] [11] [12], and photocatalyst [13] [14]. And also, it has other applications, such as piezoelectric devices, spin based electronics or spintronics, luminescent materials, and transparent conductors [6] [8] [15] [16]. Till now $\mathrm{ZnO}$ thin films have been synthesized by various techniques including sol-gel spin coating method [4], low pressure chemical vapor deposition (LPCVD) [7] [8], Chemical Both Deposition (CBD) [12], spray-pyrolysis [13] [14], thermal evaporation [17], pulsed laser deposition (PLD) [18], metal organic chemical vapor deposition (MOCVD) [19], sputtering [20], molecular beam epitaxy [21], and Hydrothermal Technique [15], etc. Spray pyrolysis is widely used because of its simplicity, commercial viability, and potential for cost-effective mass production. The spray-pyrolysis technique has been successfully applied to synthesize $\mathrm{ZnO}$ thin films and analyzed their growing characteristics, atomic composition, surface morphology, microstructure and optical properties. Spray pyrolysis method is especially efficient in producing thin films, transparent, multi-component oxide layers of many compositions on various substrates, including glass. There are many factors affecting the physical properties of $\mathrm{ZnO}$ thin films, including $\mathrm{ZnO}$ solution concentration, solvent, substrate temperature, post deposition annealing, annealing atmosphere and film thickness. The novel results derived from this situation have encouraged the researchers to increase their interest in the field of chemically sprayed $\mathrm{ZnO}$ thin films. This is the reason why we focus our attention mainly on the contributions on chemically sprayed $\mathrm{ZnO}$ thin films.

In this article, our interest is focused on adsorption and photocatalytic ability for organic dye over $\mathrm{ZnO}$ catalyst in aqueous solution. We aim to synthesize promising $\mathrm{ZnO}$ nanofibers that behave as an efficient photocatalyst by low cost spray pyrolysis technique and effects are being made to characterize the $\mathrm{ZnO}$ nanofibers using structurally, morphologically and studied its photocatalytic activity.

\section{Experimental Details}

\subsection{Materials and Chemicals}

Zinc acetate dihydrate $\left[\mathrm{Zn}\left(\mathrm{CH}_{3} \mathrm{COO}\right)_{2} \cdot 2 \mathrm{H}_{2} \mathrm{O}\right.$, Himedia, 99.5\%], double distilled water, methylene blue (MB), Glass micro slide substrates with dimensions $75 \mathrm{~mm} \times 25 \mathrm{~mm} \times$ $1.2 \mathrm{~mm}$ (Blue star, Polar Industrial Corporation, India) were applied for deposition of $\mathrm{ZnO}$ thin films by simple spray pyrolysis technique at a substrate temperature of $350^{\circ} \mathrm{C}$. 


\subsection{Synthesis of Zno Thin Films}

The $\mathrm{ZnO}$ thin films were deposited on glass substrates at a substrate temperature of $350^{\circ} \mathrm{C}$ by spray pyrolysis deposition technique. The $\mathrm{ZnO}$ precursor solution was prepared by dissolving $0.1 \mathrm{M}$ of zinc acetate dihydrate $\left[\mathrm{Zn}\left(\mathrm{CH}_{3} \mathrm{COO}\right)_{2} \cdot 2 \mathrm{H}_{2} \mathrm{O}\right.$, Himedia, 99.5\%] in $25 \mathrm{ml}$ deionized water. Before deposition the glass substrates were cleaned with detergent solution, diluted $\mathrm{HCl}$ and deionized water. Further, ultrasonic cleaning was carried out for $30 \mathrm{~min}$ in an ultrasonic bath and then rinsed in acetone for $10 \mathrm{~min}$. Then the ultrasonically cleaned substrates were placed on a sample holder facing the air-atomizing nozzle at a fixed distance of $28 \mathrm{~cm}$ in the chamber. Compressed air was used as the carrier gas at the pressure of 2 bar. The prepared solution was sprayed ( 3 $\mathrm{ml} / \mathrm{min}$ ) onto the clean glass substrates. During spray pyrolysis, a precursor solution was sprayed as fine droplets on to a heated substrate. When the droplets reach the heated substrate, they spread out and undergo pyrolytic decomposition. Finally, the solid compounds react to become a new chemical compound. The possible chemical reaction that takes place on the heated substrate to produce $\mathrm{ZnO}$ thin film may be as follows [22] [23].

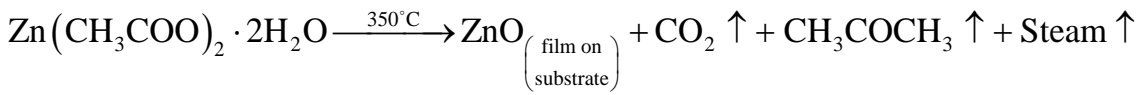

The deposited films were annealed at $450^{\circ} \mathrm{C}$ for $1 \mathrm{hr}$ in the muffle furnace using a ramp-rate of $10^{\circ} \mathrm{C}$ per minute.

\subsection{Characterization}

The structural properties and phase identification of the films were done by using X-ray diffractometer with $\mathrm{CuK}_{\alpha}$ radiation $(\lambda=1.5406 \AA$ ) (Panalytical Xpert pro) for the $2 \theta$ range from $20^{\circ}$ to $80^{\circ}$ at room temperature. The surface morphology was studied with a scanning electron microscope (ZEISS, EVO-18). Stoichiometry of the film estimated using EDX. The UV-visible optical transmission and absorption spectra of $\mathrm{ZnO}$ thin films were recorded by UV-VIS spectrophotometer (UV-3092). The photocatalytic activity was evaluated by the degradation of $\mathrm{MB}$ under visible light irradiation and optical absorption spectrum of $\mathrm{MB}$ solution was measured using a UV-Vis spectrophotometer. The thickness of the film was measured by weight difference method using the relation $t=\Delta m /(g \times A)$. Where, $\Delta m$ is the mass difference measured using micro balance i.e. mass of the substrate measured after deposition and before deposition. It is taken in grams. " $A$ " is the surface area of the film in $\mathrm{cm}^{2}$ and $\mathrm{g}$ is the density of deposited material (density of $\mathrm{ZnO}=5.61 \mathrm{gm} / \mathrm{cm}^{3}$ ). The film thickness was found to be around 1.5 $\mu \mathrm{m}$.

\section{Results and Discussion}

\subsection{Structural Properties of the ZnO Thin Films}

Figure 1, shows the phase identification and crystal structure of the $\mathrm{ZnO}$ thin films of the as prepared and annealed at $450^{\circ} \mathrm{C}$ for $1 \mathrm{hr}$. These films are found to be polycrystal- 


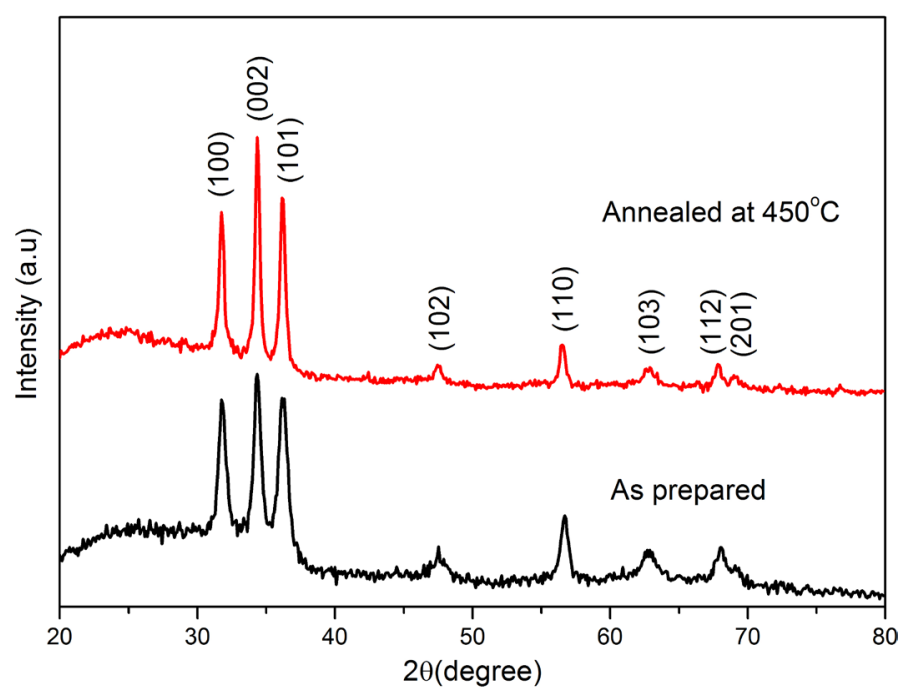

Figure 1. XRD patterns of the $\mathrm{ZnO}$ thin films.

line in nature and exhibit single phase hexagonal wurtzite structure. The observed XRD patters are compared with standard JCPDS data file (File Nos. 890510). The observed $2 \theta$ values are in good agreement with the standard ones, and having a hexagonal wurtzite structure with lattice constants $a=3.248 \AA$ and $c=5.205 \AA$. It is clearly seen from the figure that the crystallinity of $\mathrm{ZnO}$ film increases with the annealing temperature. The films showed several diffraction peaks at $2 \theta=31.808^{\circ}, 34.435^{\circ}, 36.250^{\circ}, 47.538^{\circ}$, $56.602^{\circ}, 62.795^{\circ}, 67.945^{\circ}$, and $69.120^{\circ}$ having the inter planar spacing of $2.813 \AA$, 2.605 $\AA, 2.478 \AA, 1.626 \AA, 1.480 \AA, 1.379 \AA, 1.358 \AA$ and $1.358 \AA$ with orientation of (100), (002), (101), (102), (110), (103), (112), and (201) planes respectively. The $\mathrm{ZnO}$ thin films exhibit three prominent peaks of (100), (002), and (101) plane orientations. Again, some low intensity peaks corresponding to the orientations of (102), (110), (103), (112), and (201) are also present. The annealing temperature plays an important role on the surface reactions and species mobility. The lattice constants " $a$ " and " $c$ " of the hexagonal wurtzite structure of $\mathrm{ZnO}$ films can be calculated and was found to be $a$ $=b=3.252 \AA$ and $c=5.204 \AA$ by using the given below relation [24].

$$
\frac{1}{d_{h k l}^{2}}=\frac{4}{3}\left(\frac{h^{2}+h k+k^{2}}{a^{2}}\right)+\frac{l^{2}}{c^{2}}
$$

The crystallite size has been evaluated from peak profile using full width at half maximum (FWHM) of the corresponding diffraction peak using Debye-Scherrer's formula [25].

$$
D=\frac{0.9 \lambda}{\beta \cos \theta}
$$

where " $\theta$ " is the Bragg diffraction angle, $\beta$ is the FWHM (taken in radians) of the (002) plane orientation diffraction peak and $\lambda$ is the wavelength of the incident X-ray ( $\lambda=$ $0.15406 \mathrm{~nm}$ ). The lattice strain $(\varepsilon)$ and dislocation densities $(\delta)$ were calculated using the relation given below [25]. 


$$
\begin{gathered}
\varepsilon=\frac{\beta \cos \theta}{4} \\
\delta=\frac{1}{D^{2}}
\end{gathered}
$$

The dislocation density $(\delta)$, defined as the length of dislocation lines per unit volume of the crystal and it gives more information about the crystal structure. Better the crystallization smaller will be the dislocation density. The crystallite size found to increase with increase in annealing temperature, whereas the strain and dislocation density are found to decrease.

The preferential growth orientation was determined using a texture coefficient $T C(h k)$. This factor can be calculated using the following relation [26].

$$
T C_{h k l}=\frac{I(h k l) /\left(I_{s} h k l\right)}{n^{-1} \sum_{n} I(h k l) /\left(I_{s} h k l\right)}
$$

where $\mathrm{TC}(h k l)$ is texture coefficient, $I(h k l)$ is the measured XRD intensity of a plane ( $h k l)$ obtained from the films, $I_{s}(h k l)$ is the standard intensity of the plane ( $\left.h k l\right)$ taken from the JCPDS data, and $\mathrm{n}$ is the number of diffraction peaks considered. The variations of texture coefficient calculated for the three main diffraction peaks ((100), (002) and (101)) of wurtzite $\mathrm{ZnO}$, are listed in Table 1. The texture coefficient for the (002) orientation has been found to increase from 1.476 to 1.622 with annealing temperature. The value of the texture coefficient indicates a sample with randomly oriented crystallite presents $\operatorname{TC}(h, k, I)=1$, while the larger value, the larger abundance of crystallites oriented at the $(h k l)$ direction. Thus, in the present investigation, with increase in annealing temperature, the crystallinity along (002) plane improves.

\subsection{Surface Morphology and Composition Analysis of Zno Thin Films}

Figure 2, shows the surface morphology of as deposited and annealed $\mathrm{ZnO}$ thin films. SEM micrographs reveals that the thin films were found to be crack free, having uniform texture the substrate and the films were found to be nano fiber like structure. The average diameter of the fibers for the as deposited and annealed at $450^{\circ} \mathrm{C}$ was found to be approximately $390 \mathrm{~nm}$, and $400 \mathrm{~nm}$ respectively. Ilican et al. (2006) also reported the indium-doped zinc oxide nanofibers with uniform diameter of $200 \mathrm{~nm}$ [26]. In our investigation the average diameter of the fibers increases with annealing temperature, this is probably due to agglomeration during annealing process, and producing thicker

Table 1. Microstructural parameters of $\mathrm{ZnO}$ thin film.

\begin{tabular}{cccccccc}
\hline Sample & TC (100) & $\begin{array}{c}\text { TC } \\
(\mathbf{0 0 2})\end{array}$ & $\begin{array}{c}\text { TC } \\
(101)\end{array}$ & $\begin{array}{c}\text { FWHM } \\
(\beta)(\mathrm{deg})\end{array}$ & $\begin{array}{c}\text { Crystallite } \\
\text { size }(D) \\
(\mathrm{nm})\end{array}$ & $\begin{array}{c}\text { Lattice } \\
\text { strain } \epsilon \\
\left(10^{-3}\right)\end{array}$ & $\begin{array}{c}\text { Dislocation } \\
\text { density }(\delta) \times \\
10^{-3}(\mathrm{~nm})^{-2}\end{array}$ \\
\hline $\begin{array}{c}\text { As } \\
\text { prepared }\end{array}$ & 0.968 & 1.476 & 0.556 & 0.5377 & 15.46 & 2.24 & 4.184 \\
$\begin{array}{c}\text { Annealed } \\
\text { at } 450^{\circ} \mathrm{C}\end{array}$ & 0.855 & 1.622 & 0.524 & 0.3418 & 24.23 & 1.42 & 1.691 \\
\hline
\end{tabular}

TC is the texture coefficient; FWHM is the full width at half maximum. 
diameter of fibers. Similarly it has been observed that the annealing temperature has profound influence on the diameter of the nano fibres [27]. Stoichiometry and Compositional analysis of $\mathrm{ZnO}$ thin film was carried out by the energy dispersive $\mathrm{X}$-ray spectrometer (EDX) shown in Figure 3. The EDX analysis confirmed the presence of $\mathrm{Zn}$ and $\mathrm{O}$ elements in the $\mathrm{ZnO}$ film.

\subsection{Optical Studies}

The optical properties of bulk materials and thin films that are very important for optoelectronic applications, the properties include absorbance $(A)$, transmittance $(T)$, and reflectance $(R)$, which characterize the interaction of incident radiation with a particular coating of material. These properties are also related to intrinsic properties of films such as coefficient of absorption $(\alpha)$, extinction coefficient $(k)$, refractive index $(n)$,
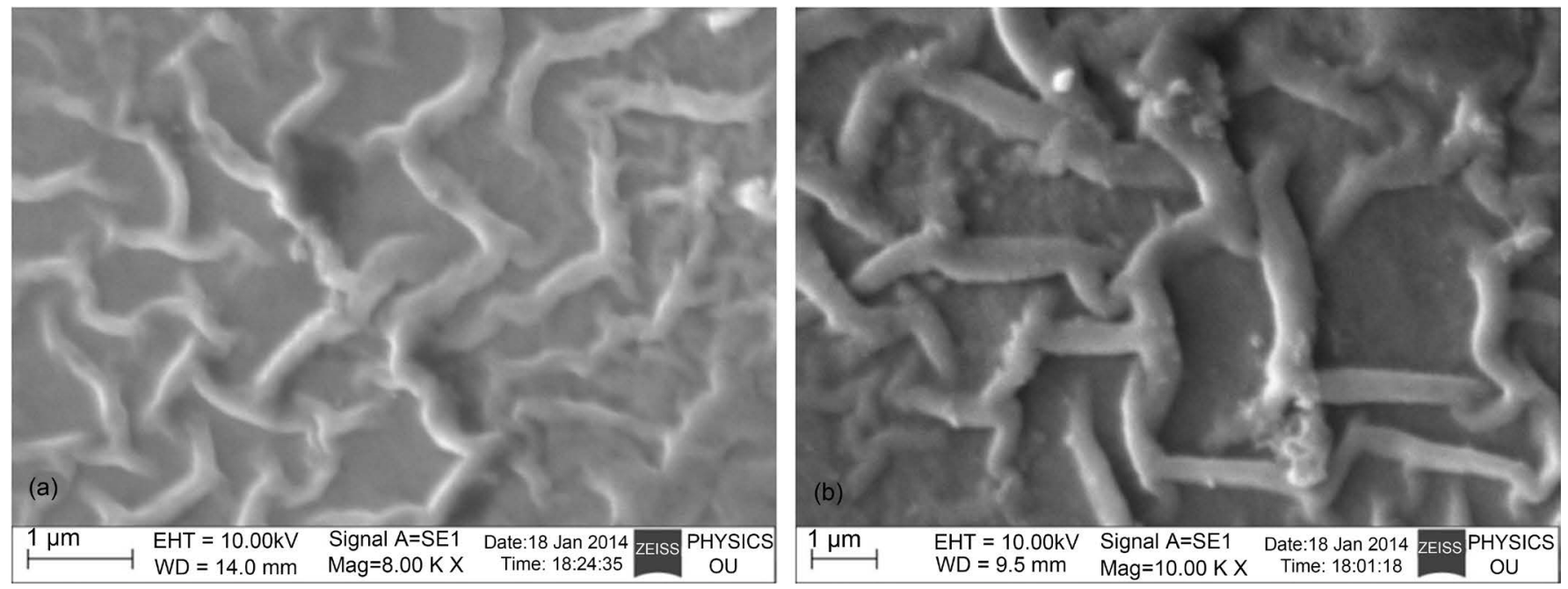

Figure 2. SEM images of $\mathrm{ZnO}$ thin films: (a) as deposited, (b) annealed at $450^{\circ} \mathrm{C}$.

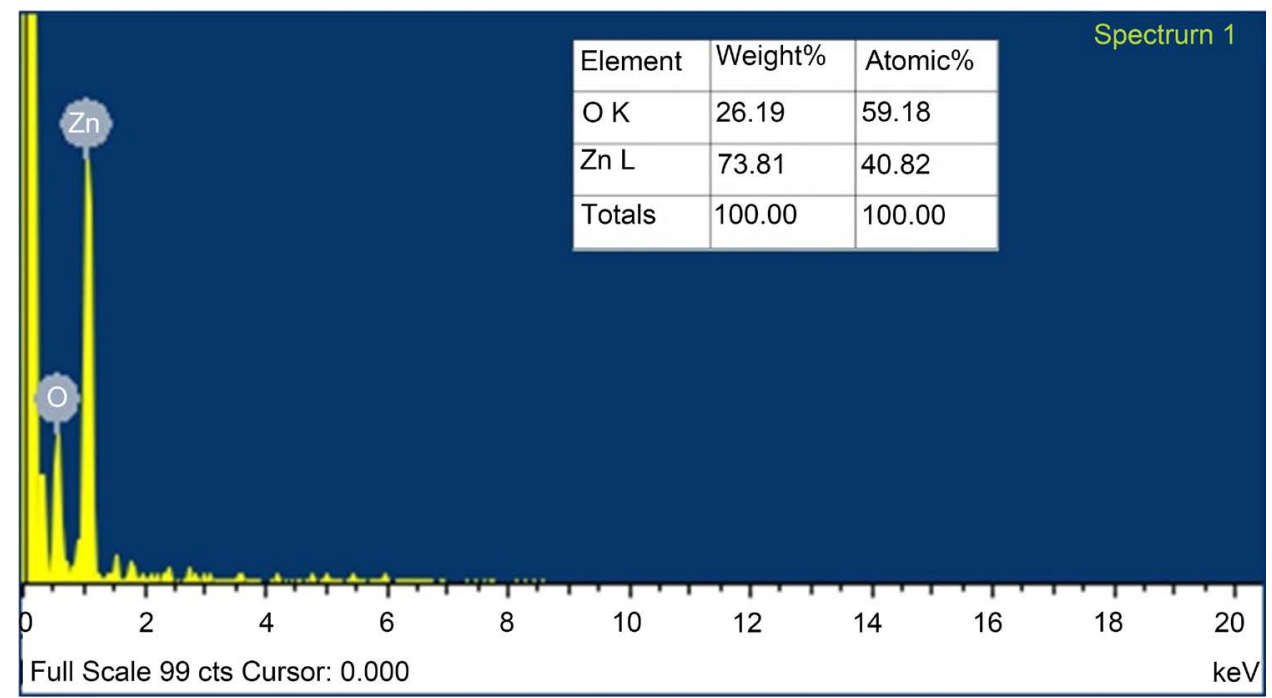

Figure 3. EDX analysis of $\mathrm{ZnO}$ thin film annealed at $450^{\circ} \mathrm{C}$. 
band gap energy and optical conductivity. In the present investigation, we calculated the absorbance and transmittance as a function of the wave length at room temperature. From the above parameters the reflectance of the films can be estimated using the following relation [28].

$$
A+T+R=1
$$

The optical transmittance and absorbance of $\mathrm{ZnO}$ films of as prepared and annealed at different temperatures shown in Figure 4(a) and Figure 4(b). Absorption spectrum indicates that the absorption of light in visible region is very low and greater in the UV region. Absorption spectra of $\mathrm{ZnO}$ thin film shows that the absorption edge is slightly moved towards longer wavelength side (red shift) with increase in annealing temperature
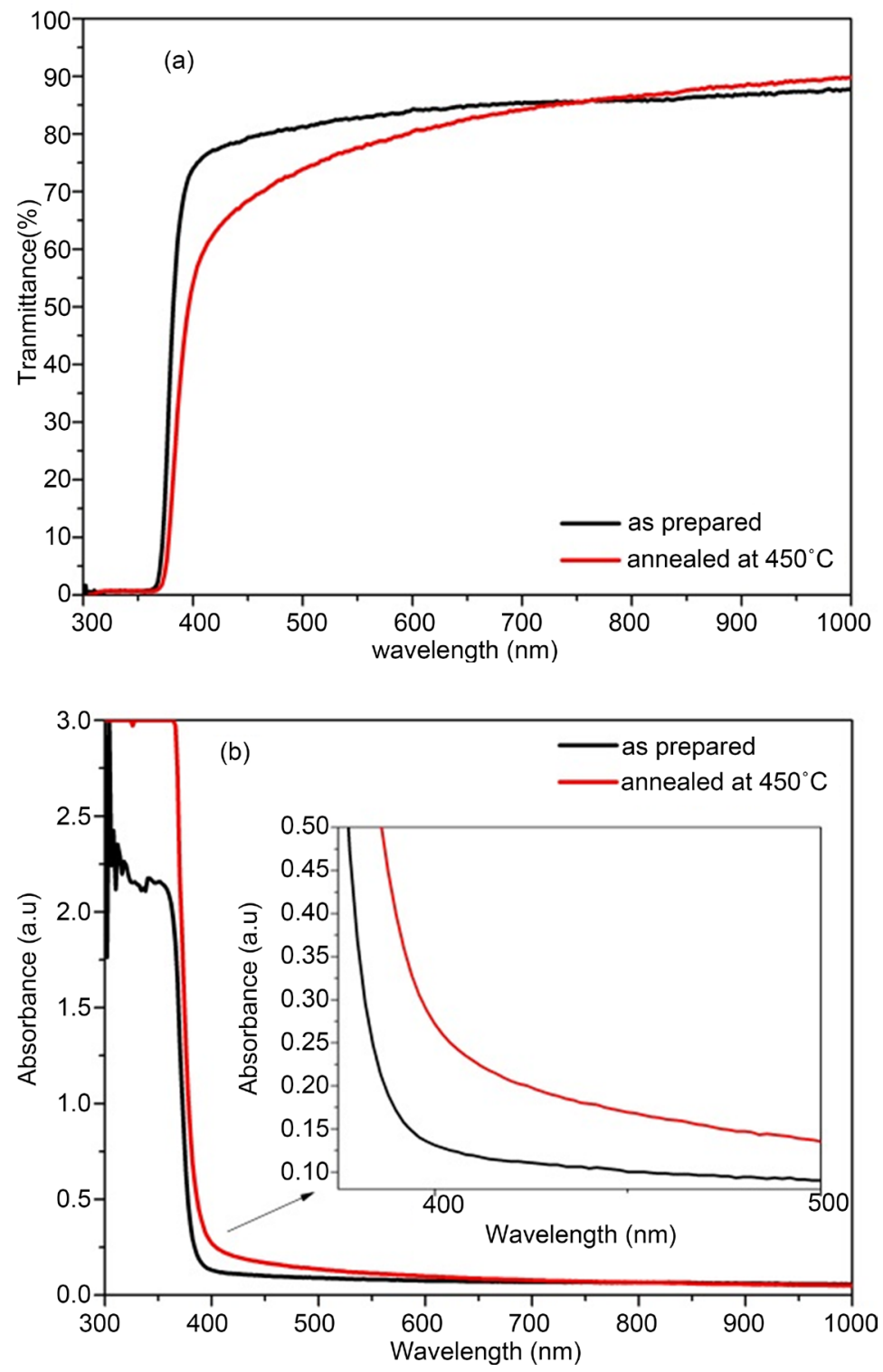

Figure 4. (a) Optical transmittance spectra of $\mathrm{ZnO}$ thin films, (b) Optical absorption spectra of $\mathrm{ZnO}$ thin films. 
due to the change in band gap of $\mathrm{ZnO}$ thin film due to change in crystallite size. $\mathrm{ZnO}$ film exhibits high transmittance $(>85 \%)$ in the visible region, the transmission of $\mathrm{ZnO}$ film is high over large wavelengths. This suggests that the produced film indicates a good optical quality due to the low scattering/ absorption losses. In nanocrystalline semiconductors, the following equation has been obtained to relate the absorption coefficient to incident photon energy $h \vartheta$. The absorption coefficient $\alpha(\lambda)$ has been calculated using Lambert's law [29] [30]

$$
\alpha(\lambda)=\frac{\ln (1 / T)}{t}
$$

where $t$ is the thickness of film. The extinction coefficient can be obtained from the relation $k=\frac{\lambda \alpha}{4 \pi}$, where $\lambda$ is the wavelength of the incident radiation impinging on the film. The extinction coefficient as a function of wavelength and it is observed that the excitation coefficient decreases with the increase of annealing temperature. This behavior of the absorption coefficient $\alpha(\lambda)$ and the extinction coefficient $(k)$ is similar to the optical absorption behavior. The Optical energy gap $E_{\mathrm{g}}$ and absorption coefficient $\alpha(\lambda)$ are related by the equation [29] [30]

$$
\alpha(\lambda) h \vartheta=B\left(h \vartheta-E_{g}\right)^{r}
$$

where $h \vartheta$ is the photon energy, $\alpha(\lambda)$ is the absorption coefficient, $E_{\mathrm{g}}$ is the optical band gap and $B$ is the slope of the tauc edge, called the band tailing parameter and the exponent " $r$ " depends on the type of optical transition, which is $1 / 2$ for direct allowed transition and 2 for indirect allowed transition. Whether the film has direct or indirect band gaps will be determined from the linearity of the plots of $(\alpha h \vartheta)^{2}$ versus $(h \vartheta)$ and $(\alpha h \vartheta)^{1 / 2}$ versus $(h \vartheta)$ respectively. Figure 5, shows the tauc plots of $\mathrm{ZnO}$ thin films. The band gap values have been calculated by extrapolating the straight line portion of the curve of $(\alpha h \vartheta)^{2}$ against $(h \vartheta)$ to meet the $\mathrm{x}$-axis. The band gap of the $\mathrm{ZnO}$ film was obtained as a direct band gap by the optical method, which was described above. Table 2 gives the values of $E_{g}$ of the $\mathrm{ZnO}$ thin films of as deposited and annealed at different temperatures. The band gap energy of the films was found to decreases with increase of annealing temperature. The change in the values of band gap energy may attribute to a decrease of the optical band gap due to interatomic distances with increasing annealing temperature on $\mathrm{ZnO}$ film [20]. The tail of the absorption edge is exponential, it indicates the presence of localized states in the band gap energy. The absorption edge gives a measure of the band gap energy and the exponential dependence of absorption coefficient $\alpha(\lambda)$ on photon energy near the band edge for many materials. This dependence is given by Urbach F., 1953 [31].

$$
\alpha(\lambda)=\alpha_{o} \exp \left(\frac{h v}{E_{u}}\right)
$$

where $\alpha_{o}$ is a constant and $E_{u}$ is Urbach energy, which is the width of the tail of the localized states corresponding to the optical transition between localized states adjacent to the valence band and extended state in the conduction band which is lying above the 


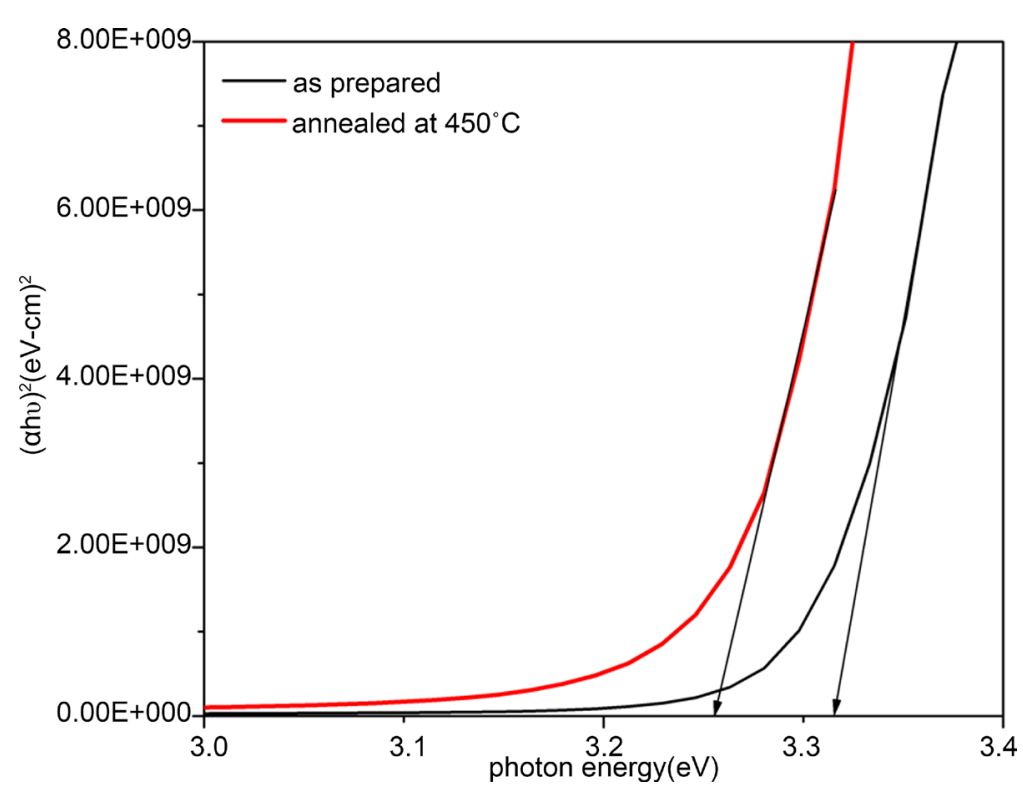

Figure 5. Plots of $(\alpha h v)^{2}$ versus photon energy $(h v)$ of $\mathrm{ZnO}$ thin films.

Table 2. Optical parameters of the $\mathrm{ZnO}$ thin film.

\begin{tabular}{|c|c|c|c|c|c|c|c|c|c|c|c|}
\hline Sample & $\begin{array}{c}E_{g} \\
(\mathrm{eV})\end{array}$ & $\begin{array}{c}E_{u} \\
(\mathrm{meV})\end{array}$ & $\begin{array}{c}E_{o} \\
(\mathrm{eV})\end{array}$ & $E_{o} / E_{g}$ & $\begin{array}{c}E_{d} \\
(\mathrm{eV})\end{array}$ & $M_{-1}$ & $\begin{array}{c}M_{-3} \\
(\mathrm{eV})^{-2}\end{array}$ & $\varepsilon_{\mathrm{s}}$ & $\begin{array}{c}\lambda_{o} \\
(\mathrm{~nm})\end{array}$ & $n_{\infty}$ & $\begin{array}{c}S_{o} \times \\
10^{13} \\
(\mathrm{~m})^{-2}\end{array}$ \\
\hline $\begin{array}{c}\text { As } \\
\text { prepared }\end{array}$ & 3.31 & 75.75 & 6.62 & 2.00 & 12.49 & 1.887 & 0.043 & 2.89 & 269 & 1.69 & 2.57 \\
\hline $\begin{array}{l}\text { Annealed } \\
\text { at } 450^{\circ} \mathrm{C}\end{array}$ & 3.26 & 95.27 & 6.04 & 1.85 & 12.38 & 2.05 & 0.056 & 3.05 & 323 & 1.75 & 1.96 \\
\hline
\end{tabular}

$E_{g}$ is the band gap energy, $E_{u}$ is the urbach energy, $E_{o}$ is the oscillatory energy, $E_{d}$ is the dispersion energy, $M_{-1}$ and $M_{-3}$ are the moments; $\varepsilon_{s}$ is the static dielectric constant, $\lambda_{o}$ is the oscillator wavelength, $S_{0}$ is the oscillator length strength.

mobility edge. The plot of $\ln \alpha$ vs. photon energy ( $h \vartheta$ ) plots for $\mathrm{ZnO}$ thin films of is shown in Figure 6. The values of $E_{\mathrm{u}}$, were obtained by taking the reciprocal of the slope of the linear region of the plots of $\ln \alpha$ versus $(h \vartheta)$ and are listed in Table 2 . In our observation, the increase in Urbach energy may be attributed to the increase of thermal induced structural disorder of the film within this temperature range.

Figure 7 , shows the plot of refractive index $(n)$ versus wavelength $(\mathrm{nm})$ of $\mathrm{ZnO}$ thin films and it indicates that the refractive index decreases with increase in wavelength. Refractive index of the films was calculated from the following relation [32].

$$
n=\frac{1+R}{1-R}+\sqrt{\left(\frac{1+R}{1-R}\right)^{2}-\left(k^{2}+1\right)}
$$

where $R$ is reflectance and $\mathrm{k}$ is extinction coefficient. The refractive index dispersion of the $\mathrm{ZnO}$ films studied can be fitted by the single-oscillator model (described by Wemple and DiDomenico, 1971). The dispersion plays an important role in the research of optical materials, because it is a significant factor in optical communication and in designing devices for spectral dispersion. The result of refractive index dispersion below 
the inter band absorption edge corresponds to the fundamental electronic excitation spectrum, according to the Wemple-DiDomenico single oscillator model, the refractive index is related to photon energy through the relationship [33] [34].

$$
n^{2}(h \vartheta)-1=\frac{E_{o} E_{d}}{E_{0}^{2}-(h \vartheta)^{2}}
$$

where $E_{o}$ and $E_{d}$ are single-oscillator parameters. Values of $E_{o}$ and $E_{d}$ can be determined from the slope $\left(1 / E_{o} E_{d}\right)$ and intercept $\left(E_{o} / E_{d}\right)$ on vertical axis of the curves of $\left(n^{2}-1\right)^{-1}$ vs. $(h \vartheta)^{2}$ by fitting a linear function to the smaller energy data shown

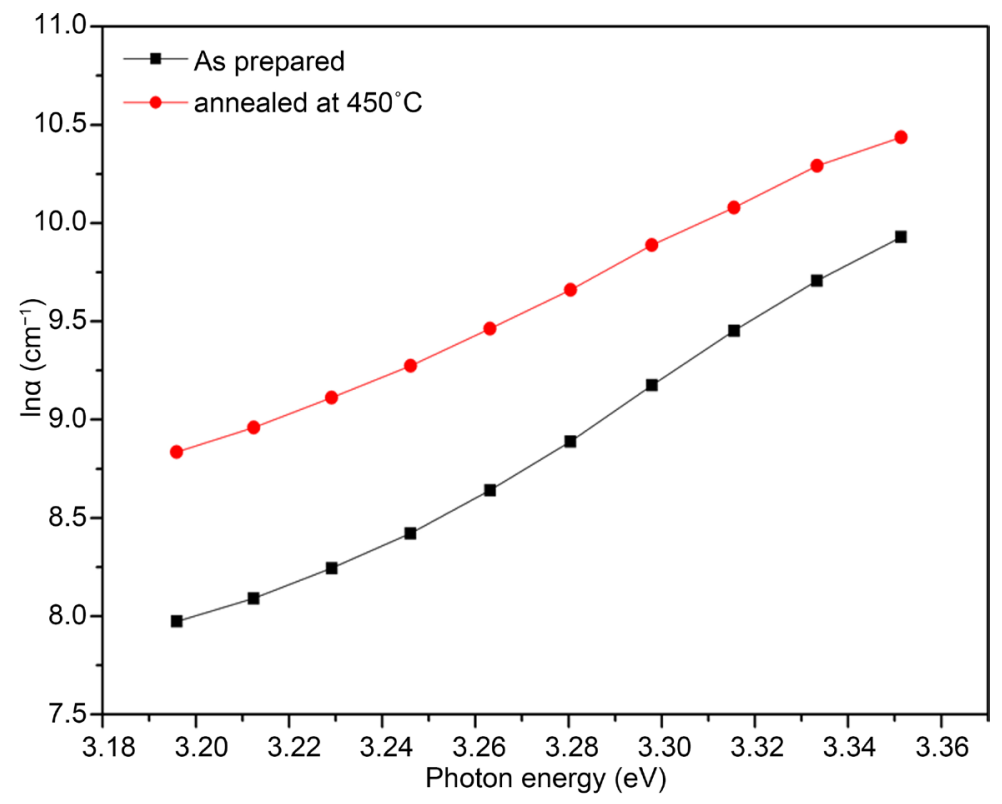

Figure 6. Plots of $\ln \alpha$ versus photon energy ( $h v)$ of $\mathrm{ZnO}$ thin films.

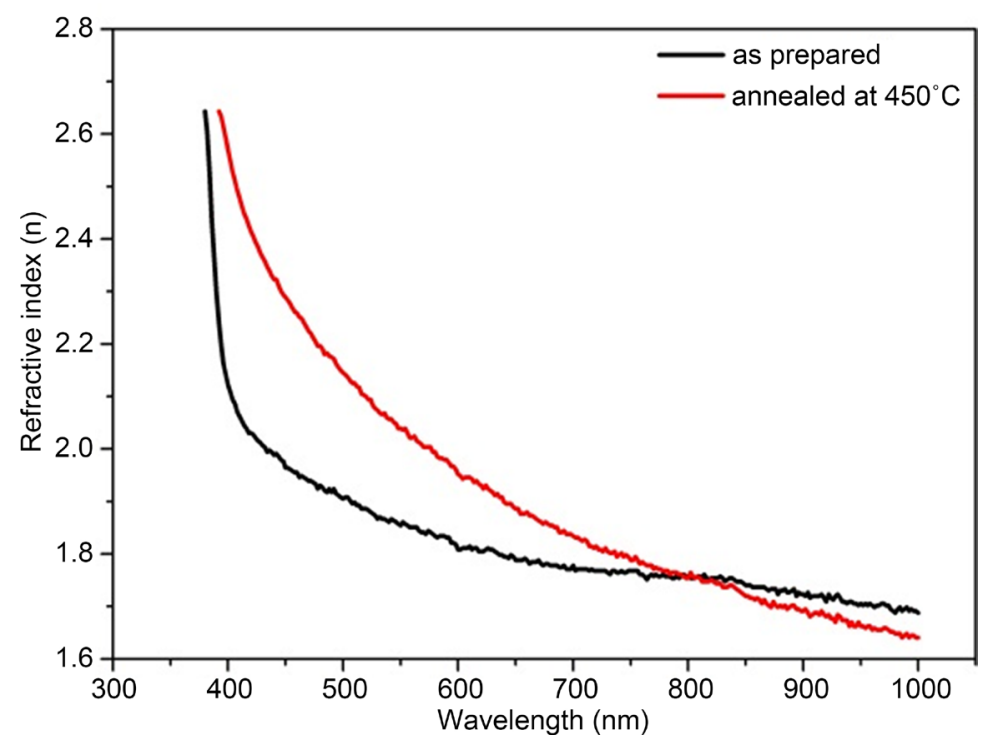

Figure 7. The refractive index plots of $\mathrm{ZnO}$ thin films. 
In Figure 8 and they are given in Table 2. The oscillator energy $E_{o}$ is average excitation energy for electronic transitions. The dispersion energy $E_{d}$ which is measure of the average strength of inter band optical transitions or the oscillator strength are single oscillator parameters. We found that the $E_{o}$ values of the deposited film is related empirically to the lowest direct band gap by $E_{o} \approx 2 E_{g} . E_{o}$ values decreased with an increase in annealing temperature. According to the single-oscillator model, the single oscillator parameters $E_{o}$ and $E_{d}$ are related to the imaginary part of the complex dielectric constant. The static (zero frequency) refractive index $n(0)=\left(1+E_{d} / E_{o}\right)^{1 / 2}$ and the static dielectric constant $\left(\varepsilon_{s}=n^{2}(0)\right)$ were calculated using Equation (11). The calculated values of the oscillator energies $\left(E_{o}\right)$, the dispersion energies $\left(E_{d}\right)$, and $\varepsilon_{\mathrm{s}}$ for the $\mathrm{ZnO}$ thin film are summarized in Table 2. The refractive index is represented by a single Sellmeier oscillator at low energies and the refractive index was also analyzed to determine the long wavelength refractive index $\left(n_{\infty}\right)$, average inter band oscillator wavelength $\left(\lambda_{o}\right)$ and the average oscillator length strength $\left(S_{o}\right)$ parameters, for the $\mathrm{ZnO}$ thin films. These parameters can be determined by using the following equation [35].

$$
\frac{\left(n_{\infty}^{2}-1\right)}{\left(n^{2}-1\right)}=1-\left(\frac{\lambda_{o}}{\lambda}\right)^{2}
$$

where $\left(n_{\infty}\right)$, and $\lambda_{o}$ values were calculated from intercept and the slope of the linear region of the plots of $\left(n^{2}-1\right)^{-1}$ vs $(\lambda)^{-2}$ and are given in Table 2.

Rearranging of Equation (12), gives [36]

$$
\left(n^{2}-1\right)=\frac{\left(S_{o} \lambda_{o}^{2}\right)}{1-\left(\frac{\lambda_{o}}{\lambda}\right)^{2}}
$$

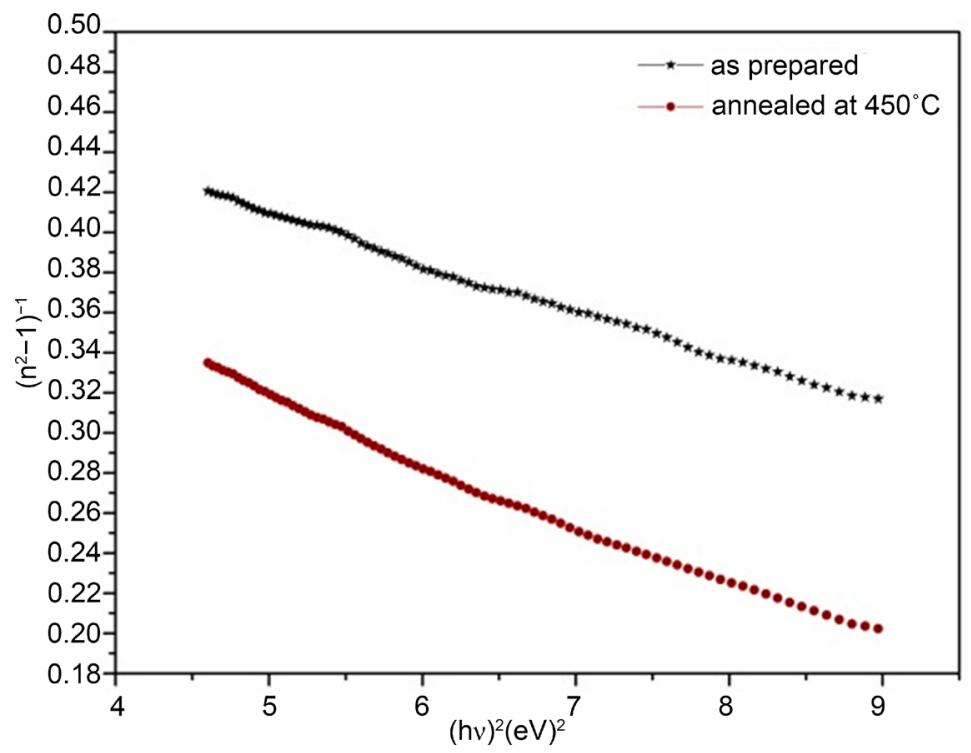

Figure 8. The plots of $\left(n^{2}-1\right)^{-1}$ versus $(h v)^{2} \mathrm{ZnO}$ thin films. 
where

$$
S_{o}=\left(n_{\infty}^{2}-1\right) / \lambda_{o}^{2}
$$

The $S_{o}$ values for $\mathrm{ZnO}$ films were obtained using above equation and are given in Table 2. The $M_{-1}$ and $M_{-3}$ moments of the imaginary part of the optical spectrum can be obtained from the relations [33]:

$$
E_{o}^{2}=\frac{M_{-1}}{M_{-3}}, E_{d}^{2}=\frac{M_{-1}^{3}}{M_{-3}}
$$

The $M_{-1}$ and $M_{-3}$ moments were calculated using Equation (15) and the obtained values are given in Table 2. The $M_{-1}$ and $M_{-3}$ moments changed due to the formation coordination of complex. It is found that $M_{-1}$ and $M_{-3}$ values increase with increase in annealing temperature.

\subsection{Evaluation of Photocatalytic Activity}

Figure 9(a), shows optical absorption spectrum of MB solution, before and after degradation under $\mathrm{ZnO}$ thin films. It revealed that the absorbance intensity of $\mathrm{MB}$ decreases obviously under visible light irradiation, which indicates that $\mathrm{MB}$ has been photodegraded. However, without light illumination, in the presence of $\mathrm{ZnO}$ film, and illumination in the absence of $\mathrm{ZnO}$ film does not result in the photocatalytic degradation of MB solution. A $200 \mathrm{~W}$ tungsten filament bulb was used as a light soure. The standard solution of methylene blue with the concentration of $1 \times 10^{-6} \mathrm{M}$ was used as a model pollutant organic dye to determine the photocatalytic efficiency of the prepared photocatalist. Photodegradation experiment was carried out by the $\mathrm{ZnO}$ film immersed into $15 \mathrm{ml}$ of $\mathrm{MB}$ solution and it was stirred in the dark in order to reach adsorption desorption equilibrium between $\mathrm{MB}$ and dissolved oxygen before irradiation and the beaker was kept in a chamber under visible light irradiation for different exposition times. Optical absorption spectrum of $\mathrm{MB}$ solution was measured using a UV-Vis spectrophotometer. The degradation efficiency was calculated using the following equation [37]

$$
\text { degradation }(\%)=\frac{C_{o}-C}{C_{o}} \times 100=\frac{A_{o}-A}{A_{o}} \times 100
$$

where $C_{\mathrm{o}}$ and $C$ represent the initial concentration, after the adsorption-desorption equilibrium and at the reaction time $(t)$ concentration of $\mathrm{MB}$ solution, respectively. $A_{\mathrm{o}}$ represents the initial absorbance, and $A$ represents the changed absorbance of the MB solution at the characteristic absorption wavelength of $666 \mathrm{~nm}$. The performance of degradation of as deposited and annealed $\mathrm{ZnO}$ films were reached to $90 \%$ and $93 \%$ after 240 min respectively. The highest catalytic activity was obtained by annealed $\mathrm{ZnO}$ catalyst due to the lower band gap energy. In addition, the relationship between the irradiation time and degradation reaction rate obeys the first-order reaction kinetic model, which could be well explained in terms of the Langmuir-Hinshelwood mechanism [37]. The kinetics can be expressed as 


$$
\ln \left(\frac{C}{C_{o}}\right)=-k_{a p p}
$$

where $C$ and $C_{o}$, represent changed concentration and initial concentration of $\mathrm{MB}$, $k_{a p p}$ and $t$ is the apparent rate kinetic constant and irradiation time, respectively. The plot of $-\ln \left(\frac{C}{C_{o}}\right)$ versus irradiation time $(t)$ for $\mathrm{ZnO}$ is shown in Figure $9(\mathrm{~b})$. Obtained kinetic plots are linear, which confirms that the photodegradation reaction of $\mathrm{MB}$ on $\mathrm{ZnO}$ is well fitted to the pseudo-first order reaction kinetics. The photocatalytic reaction rate constant $\left(k_{a p p}\right)$ value for catalyst was estimated from the slop of this
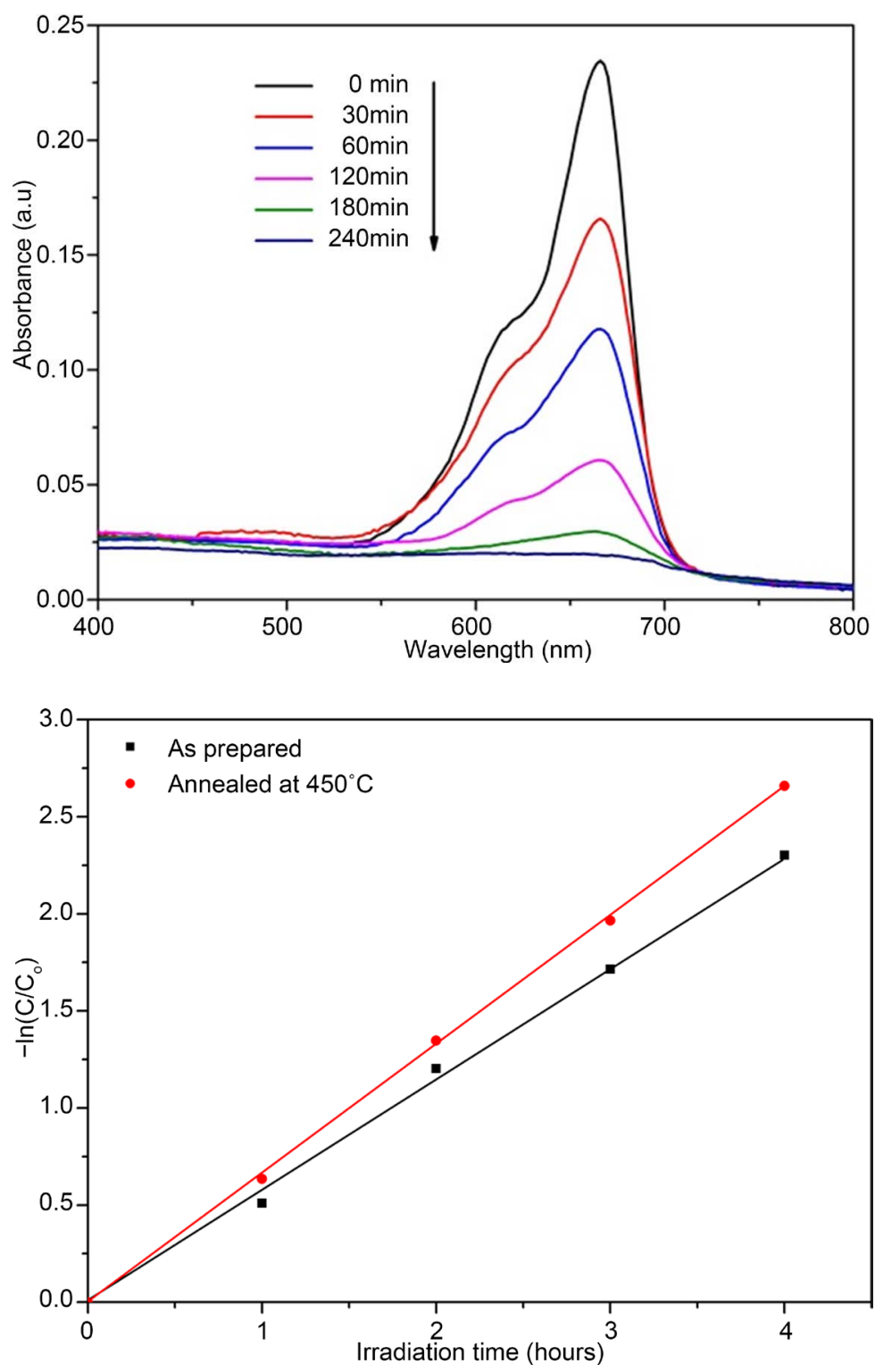

Figure 9. (a) Absorption spectra of $\mathrm{MB}$ catalyzed at room temperature in the presence of $\mathrm{ZnO}$ film annealed at $450^{\circ} \mathrm{C}$, (b). The first order kinetics of the degradation of Methylene Blue dye with irradiation time. 
linear plots and it were found to $0.0097 \mathrm{~min}^{-1}$ and $0.0111 \mathrm{~min}^{-1}$ for as deposited and annealed films respectively. It is clear that the catalytic activity higher for annealed $\mathrm{ZnO}$. Therefore, the $\mathrm{ZnO}$ nanofibers with a low band gap can significantly increase the catalytic activity. However, the kinetic constant of the catalyst become smaller with greater band gap, because the opacity and light scattering of the $\mathrm{ZnO}$ nanofibers decrease the absorption of incident light and decrease catalytic active sites.

\section{Conclusion}

Visible light responsive zinc oxide films were deposited on glass substrate at a temperature of $350^{\circ} \mathrm{C}$ by chemical spray pyrolysis technique. The first order kinetic rate constant has been determined from the $\mathrm{MB}$ degradation measurement. $\mathrm{ZnO}$ film exhibits high catalytic activity for lower band gap energy. The lattice constants of hexagonal wurtzite structure $\mathrm{ZnO}$ films were calculated as $3.252 \AA$ and $5.204 \AA$. Crystallite size has been found increase from $15 \mathrm{~nm}$ to $24 \mathrm{~nm}$ with annealing temperature. The SEM images of the films shown nano fiber like structure morphology and the average diameter of the fibers were $\sim 390 \mathrm{~nm}$ and $\sim 400 \mathrm{~nm}$ as deposited and annealed at $450^{\circ} \mathrm{C}$ respectively. The films exhibit low absorbance in the visible/near infrared (NIR) region from $\sim 390 \mathrm{~nm}$ to $1000 \mathrm{~nm}$. The direct optical band gap is $3.31 \mathrm{eV}$ for deposited and $3.26 \mathrm{eV}$ for annealed films. The oscillator energy $\left(E_{o}\right)$, and the dispersion energy $\left(E_{d}\right)$ of the $\mathrm{ZnO}$ thin films were determined. The values of oscillator energy $\left(E_{\mathrm{o}}\right)$ decrease, and the $M_{-1}$ and $M_{-3}$ optical moments increase with increasing annealing temperature. The long wavelength refractive index $n_{\infty}$, average inter band oscillator wavelength $\left(\lambda_{o}\right)$ and the average oscillator length strength $\left(S_{o}\right)$ parameters are found to be function of annealing temperature. The optical constants (refractive index $n$, extinction coefficient $k$, band gap energy and dielectric constant) of the as-deposited and annealed films were analyzed from the transmittance and reflectance spectra. Based on the observed data $\mathrm{ZnO}$ thin films are found to be a promising candidate for opto-electronic device and potential applications in the field of environmental remediation and photocatalysis.

\section{Acknowledgements}

One of the authors D. Komaraiah, thank the University Grants Commission, New Delhi for awarding the SRF, under the UGC scheme of RFSMS and also the authors R. Sayanna and M.V. Ramana Reddy, thank the UGC-UPE-FAR-OU for providing financial assistance to carry out this work.

\section{References}

[1] Zhang, Y., Wu, C., Zheng, Y. and Guo, T. (2012) Synthesis and Efficient Field Emission Characteristics of Patterned ZnO Nanowires. Journal of Semiconductors, 33, 023001. http://dx.doi.org/10.1088/1674-4926/33/2/023001

[2] Song, J.Z., He, Y., Chen, J., Zhu, D., Pan, Z.D., Zhang, Y.F. and Wang, J.-A. (2012) Bicolor Light-Emitting Diode Based on Zinc Oxide Nanorod Arrays and Poly(2-Methoxy,5Octoxy)-1,4-Phenylenevinylene. Journal of Electronic Materials, 41, 431-436. http://dx.doi.org/10.1007/s11664-011-1783-x 
[3] Fortunato, E., Barquinha, P., Pimentel, A., Goncalves, A., Marques, A., Pereira, L. and Martins, R. (2005) Recent Advances in ZnO Transparent Thin Film Transistors. Thin Solid Films, 487, 205-211. http://dx.doi.org/10.1016/j.tsf.2005.01.066

[4] You, H.-C. (2013) Indium Doping Concentration Effects in the Fabrication of Zinc-Oxide Thin-Film Transistors. International Journal of Electrochemical Science, 8, 9773-9784.

[5] Suzuoki, Y., Ohki, A., Mizutani, T. and Ieda, M. (1987) Electrical Properties of $\mathrm{ZnO}^{-\mathrm{Bi}_{2} \mathrm{O}_{3}}$ Thin-Film Varistors. Journal of Physics D: Applied Physics, 20, 511-517. http://dx.doi.org/10.1088/0022-3727/20/4/017

[6] Müller, J., Rech, B., Springer, J. and Vanecek, M. (2004) TCO and Light Trapping in Silicon Thin Film Solar Cells. Solar Energy, 77, 917-930. http://dx.doi.org/10.1016/j.solener.2004.03.015

[7] Kim, D., Yun, I. and Kim, H. (2010) Fabrication of Rough Al Doped ZnO Films Deposited by Low Pressure Chemical Vapor Deposition for High Efficiency Thin Film Solar Cells. Current Applied Physics, 10, S459-S462. http://dx.doi.org/10.1016/j.cap.2010.02.030

[8] Faÿ, S., Steinhauser, J., Nicolay, S. and Ballif, C. (2010) Polycrystalline ZnO: B Grown by LPCVD as TCO for Thin Film Silicon Solar Cells. Thin Solid Films, 518, 2961-2966. http://dx.doi.org/10.1016/j.tsf.2009.09.189

[9] Badadhe, S.S. and Mulla, I.S. (2009) $\mathrm{H}_{2} \mathrm{~S}$ Gas Sensitive Indium-Doped ZnO Thin Films: Preparation and Characterization. Sensors and Actuators B, 143, 164-170. http://dx.doi.org/10.1016/j.snb.2009.08.056

[10] Kruefua, V., Liewhiranb, C., Wisitsoraatc, A. and Phanichphantd, S. (2011) Selectivity of Flame-Spray-Made $\mathrm{Nb} / \mathrm{ZnO}$ Thick Films towards $\mathrm{NO}_{2}$ Gas. Sensors and Actuators $B, 156$, 360-367. http://dx.doi.org/10.1016/j.snb.2011.04.046

[11] Shewale, P.S., Agawane, G.L., Shin, S.W., Moholkar, A.V., Lee, J.Y., Kim, J.H. and Uplane, M.D. (2013) Thickness Dependent $\mathrm{H}_{2} \mathrm{~S}$ Sensing Properties of Nanocrystalline ZnO Thin Films Derived by Advanced Spray Pyrolysis. Sensors and Actuators B, 177, 695-702. http://dx.doi.org/10.1016/j.snb.2012.11.076

[12] Dhawale, D.S., Dubal, D.P., More, A.M., Gujar, T.P. and Lokhande, C.D. (2010) Room Temperature Liquefied Petroleum Gas (LPG) Sensor. Sensors and Actuators B, 147, 488494. http://dx.doi.org/10.1016/j.snb.2010.02.063

[13] Shinde, S.S., Bhosale, C.H. and Rajpure, K.Y. (2012) Photocatalytic Degradation of Toluene Using Sprayed N-Doped ZnO Thin Films in Aqueous Suspension. Journal of Photochemistry and Photobiology B: Biology, 113, 70-77. http://dx.doi.org/10.1016/j.jphotobiol.2012.05.008

[14] Kaneva, N., Stambolova, I., Blaskov, V., Dimitriev, Y., Bojinova, A. and Dushkin, C. (2012) A Comparative Study on the Photocatalytic Efficiency of ZnO Thin Films Prepared by Spray Pyrolysis and Sol-Gel Method. Surface \& Coatings Technology, 207, 5-10. http://dx.doi.org/10.1016/j.surfcoat.2011.10.020

[15] Sahoo, T., Jang, L., Jeon, J., Kim, M., Kim, J., Lee, I., Kwak, J. and Lee, J. (2010) Photoluminescence Properties of $\mathrm{ZnO}$ Thin Films Grown by Using the Hydrothermal Technique. Journal of the Korean Physical Society, 56, 809-812. http://dx.doi.org/10.3938/jkps.56.809

[16] Gardeniers, J.G.E., Rittersma, Z.M. and Burger, G.J. (1998) Preferred Orientation and Piezoelectricity in Sputtered ZnO Films. Journal of Applied Physics, 83, 7844-7854. http://dx.doi.org/10.1063/1.367959

[17] Zhang, Y.A., et al. (2012) Synthesis and Efficient Field Emission Characteristics of Patterned $\mathrm{ZnO}$ Nanowires. Journal of Semiconductors, 33, 023001. http://dx.doi.org/10.1088/1674-4926/33/2/023001 
[18] Taabouche, A., et al. (2013) Effect of Substrates on the Properties of ZnO Thin Films Grown by Pulsed Laser Deposition. Advances in Materials Physics and Chemistry, 3, 209-213. http://dx.doi.org/10.4236/ampc.2013.34031

[19] Lee, C.-H. and Kim, D.-W. (2013) Thickness Dependence of Microstructure and Properties of ZnO Thin Films Deposited by Metal-Organic Chemical Vapor Deposition Using Ultrasonic Nebulization. Thin Solid Films, 546, 38-41. http://dx.doi.org/10.1016/j.tsf.2013.05.029

[20] Saha, B., et al. (2014) Combined Effect of Oxygen Deficient Point Defects and Ni Doping in Radio Frequency Magnetron Sputtering Deposited ZnO Thin Films. Thin Solid Films, 562, 37-42. http://dx.doi.org/10.1016/j.tsf.2014.03.038

[21] Wang, H., Liao, C., Chueh, Y., Lai, C., Chen, L. and Tsiang, R.C. (2013) Synthesis and Characterization of $\mathrm{ZnO} / \mathrm{ZnMgO}$ Multiple Quantum Wells by Molecular Beam Epitaxy. Optical Materials Express, 3, 237-247. http://dx.doi.org/10.1364/OME.3.000237

[22] Silva, T.G., Silveira, E., Ribeiro, E., Machado, K.D., Mattoso, N. and Hümmelgen, I.A. (2014) Structural and Optical Properties of ZnO Films Produced by a Modified Ultrasonic Spray Pyrolysis Technique. Thin Solid Films, 551, 13-18. http://dx.doi.org/10.1016/j.tsf.2013.11.011

[23] Hiltunen, L., Leskela, M., Makela, M. and Niinisto, L. (1987) Crystal Structure of $\mu_{4}$-Oxo-Hexakis ( $\mu$-Acetato) Tetrazinc and Thermal Studies of Its Precursor, Zinc Acetate Dihydrate. Acta Chemica Scandinavica, 41A, 548-555. http://dx.doi.org/10.3891/acta.chem.scand.41a-0548

[24] Cullity, B.D. (1987) Elements of X-Ray Diffraction. Addison-Wesley Publishing Company Inc., London.

[25] Sridhar, R., Manoharan, C., Ramalingam, S., Dhanapandian, S. and Bououdina, M. (2014) Spectroscopic Study and Optical and Electrical Properties of Ti-Doped ZnO Thin Films by Spray Pyrolysis. Spectrochimica Acta Part A: Molecular and Biomolecular Spectroscopy, 120, 297-303. http://dx.doi.org/10.1016/j.saa.2013.09.149

[26] Ilicana, S., Caglara, Y., Caglara, M. and Yakuphanoglu, F. (2006) Electrical Conductivity, Optical and Structural Properties of Indium-Doped ZnO Nanofiber Thin Film Deposited by Spray Pyrolysis Method. Physica E, 35, 131-138. http://dx.doi.org/10.1016/j.physe.2006.07.009

[27] Maity, R., Das, S., Mitra, M.K. and Chattopadhyay, K.K. (2005) Synthesis and Characterization of ZnO Nano/Microfibers Thin Films by Catalyst Free Solution Route. Physica E, 25, 605-612. http://dx.doi.org/10.1016/j.physe.2004.09.002

[28] Willey, R.R. (1936) Field Guide to Optical Thin Films. SPIE Press, Bellingham.

[29] Moss, T.S. (1961) Optical Properties of Solids. Butterworths, London, 34.

[30] Tauc, J. (1974) Amorphous and Liquid Semiconductors. Springer, New York, Ch. 4. http://dx.doi.org/10.1007/978-1-4615-8705-7

[31] Urbach, F. (1953 The Long-Wavelength Edge of Photographic Sensitivity and of the Electronic Absorption of Solids. Physical Review, 92, 1324. http://dx.doi.org/10.1103/PhysRev.92.1324

[32] Pankove, J.I. (1971) Optical Processes in Semiconductors. Dover, New York, 93.

[33] Wemple, S.H. and DiDomenico Jr., M. (1971) Behavior of the Electronic Dielectric Constant in Covalent and Ionic Materials. Physical Review B, 3, 1338-1351. http://dx.doi.org/10.1103/PhysRevB.3.1338

[34] Wemple, S.H. (1972) Refractive-Index Behavior of Amorphous Semiconductors and Glasses. Physical Review B, 7, 3767-3777. http://dx.doi.org/10.1103/PhysRevB.7.3767 
[35] Wolaton, A.K. and Moss, T.S. (1963) Determination of Refractive Index and Correlation to Effective Electron Mass in PbTe and PbSe. Proceedings of the Royal Society, 81, 509. http://dx.doi.org/10.1088/0370-1328/81/3/319

[36] Lee, P.A., Said, G., Davis, R. and Lim, T.H. (1969) On the Optical Properties of Some Layer Compounds. Journal of Physics and Chemistry of Solids, 30, 2719-2729.

http://dx.doi.org/10.1016/0022-3697(69)90045-6

[37] Bizarro, M. and Martinez-Padilla, E. (2014) Visible Light Responsive Photocatalytic ZnO: Al Films Decorated with Ag Nanoparticles. Thin Solid Films, 553, 179-183.

http://dx.doi.org/10.1016/j.tsf.2013.10.059

Submit or recommend next manuscript to SCIRP and we will provide best service for you:

Accepting pre-submission inquiries through Email, Facebook, LinkedIn, Twitter, etc. A wide selection of journals (inclusive of 9 subjects, more than 200 journals)

Providing 24-hour high-quality service

User-friendly online submission system

Fair and swift peer-review system

Efficient typesetting and proofreading procedure

Display of the result of downloads and visits, as well as the number of cited articles

Maximum dissemination of your research work

Submit your manuscript at: http://papersubmission.scirp.org/

Or contact mrc@scirp.org 